Article

\title{
Preparation and Characterization of Potato Starch Film with Various Size of $\mathrm{Nano}_{-} \mathrm{SiO}_{2}$
}

\author{
Rongfei Zhang, Xiangyou Wang * and Meng Cheng
}

Department of Food Science and Engineering, Shandong University of Technology, Zibo 255000, China; shenggongrongfei@163.com (R.Z.); chengmeng0110@163.com (M.C.)

* Correspondence: wxy@sdut.edu.cn; Tel.: +86-0533-278-0897

Received: 28 September 2018; Accepted: 19 October 2018; Published: 22 October 2018

\begin{abstract}
The various sizes $(15,30,80$, and $100 \mathrm{~nm})$ of nano- $\mathrm{SiO}_{2}$ / potato starch films were synthesized and characterized. The gas permeability, antibacterial properties, and mechanical properties of the films were evaluated to their potential for application as food packaging materials. Results indicated that the $100 \mathrm{~nm}$ nano- $\mathrm{SiO}_{2}$ was well dispersed in the starch matrix, which induced an active group on the surface of $100 \mathrm{~nm}$ nano- $\mathrm{SiO}_{2}$ adequately combined with starch macromolecule. The water resistance and mechanical properties of the films were improved with the addition of nano- $\mathrm{SiO}_{2}$. Notably, resistance to ultraviolet and thermal aging was also enhanced. The nano- $\mathrm{SiO}_{2} /$ potato starch films were more efficient against Escherichia coli (E. coli) than Staphylococcus aureus (S. aureus). Remarkable preservation properties of the films packaging the white mushrooms were obtained, with those of the $100 \mathrm{~nm}$ films considered superior. This study can significantly guide the rational choice of the nano- $\mathrm{SiO}_{2}$ size to meet the packaging requirements of various agricultural products.
\end{abstract}

Keywords: potato starch films; nano- $\mathrm{SiO}_{2}$; antibacterial property; size

\section{Introduction}

The use of starch films shows a rational use of natural resources and reduces environmental pollution. Starch films present many advantages, such as low cost, renewability, biodegradability, and ease of processing. The starch films are exploited as a promising kind of commercial preservation films for extending the shelf of food. Different kinds of starch have been widely used to prepare the films [1-4]. Therein, potato starch presents better film-forming properties than that of other cereal starch prepared films [5]. However, the use of potato starch with $80 \%$ large macromolecules of branched amylopectin presents several disadvantages in packaging-poor moisture sensitivity, poor mechanical properties, and poor solubility [6]. Therefore, potato starch films exhibit low food preservation efficiency.

To enhance the properties of potato starch films, the surface hydroxyl groups and small size of the nanoparticles were considered. The superiority of potato starch-based nanocomposite films is attributed to the uniform dispersion of nanoparticles in the potato starch and hydrogen bonding with starch molecules through surface hydroxyl groups [7]. These qualities allow the enhancement of permeability and mechanical properties. According to related studies, the size, shape, and hydrophily of modified nanoparticles could be adjusted to improve the properties of films [8]. Several nanoparticles, such as nano- $\mathrm{ZnO}$, nano- $\mathrm{TiO}_{2}$, nano- $\mathrm{SiO}_{2}$, and nano-clay, have been evaluated as potential nanomaterial [6,9-12]. Among these nanomaterials, nano- $\mathrm{SiO}_{2}$ exhibits the greatest potential because of its superior properties, including an extremely porous structure and high surface activity. Moreover, nano- $\mathrm{SiO}_{2}$ is chemically inert and biocompatible, and prevents bacterial attack in vitro and in vivo [13]. Therefore, nano- $\mathrm{SiO}_{2}$ polymer films can maintain acceptable levels of sensorial and physiological qualities and a longer storage life for food. Song et al. (2016) [14] found 
that chitosan/nano-silica coating could reduce sugars and induce high antioxidant enzyme activities to improve chilling tolerance in loquat fruit. The chitosan/nano-silica coating could also extend the storage period of fresh longan fruits [15]. However, most studies on nano- $\mathrm{SiO}_{2}$ polymer films focused on the effect of nano- $\mathrm{SiO}_{2}$ dosage on preservation properties [16]. Meanwhile, the hydrophilic surface of nano- $\mathrm{SiO}_{2}$ in the films was modified. Despite such a modification, the original size of nano-SiO $\mathrm{S}_{2}$ limited the modified efficiency of the films. Therefore, modification costs should be reduced, and the original size of nano-SiO${ }_{2}$ should be controlled. Several studies found that nano- $\mathrm{SiO}_{2}$ dispersion facilitated synthesis in situ [17]. The effect of nano- $\mathrm{SiO}_{2}$ size on its dispersion in films has been rarely reported. In addition, nano- $\mathrm{SiO}_{2}$ exhibits a reflectivity of $70 \%-80 \%$ for ultraviolet light (wavelength number $\leq 490 \mathrm{~nm}$ ), which is incorporated into the potato starch film to resist ultraviolet aging and thermal aging $[16,18]$. Meanwhile, nano- $\mathrm{SiO}_{2}$ could also induce cytotoxicity and protein alteration in cells [19]. The cytotoxicity of nano- $\mathrm{SiO}_{2}$ was influenced by its size. The films with nano- $\mathrm{SiO}_{2}$ of different sizes might exert certain effects on microorganisms. Studies are rarely reported on the antibacterial property of nano- $\mathrm{SiO}_{2}$ polymer films with nano- $\mathrm{SiO}_{2}$ of different sizes.

The particle size is a key factor for affecting a number of technical performances and practical applications of nano-SiO${ }_{2}$. For the integration of nano- $\mathrm{SiO}_{2}$ into polymer films, the separation of film particles from one another, in addition to particle size, is important. The aggregates could reduce the properties of the films [20]. The particle size and uniformity of nano- $\mathrm{SiO}_{2}$ in the films significantly affect the performance of the films. The demand for monodisperse nano- $\mathrm{SiO}_{2}$ particles with a narrow particle size distribution is increasing. However, as the nano- $\mathrm{SiO}_{2}$ size decreases, the surface energy gradually increases. When the particle size is $25 \mathrm{~nm}$ or less, the absolute value of the surface potential of the particles and the stability of the nano- $\mathrm{SiO}_{2}$ colloidal system are reduced; in addition, electrostatic repulsion between the particles is reduced. Consequently, agglomeration occurs between nano- $\mathrm{SiO}_{2}$ particles to decrease its monodispersity. Studies on the effect of suitable particle size on the performance of nano- $\mathrm{SiO}_{2}$ / potato starch films have thus far been rarely reported. Most studies mainly aim to enhance the properties of the film by modifying the nano- $\mathrm{SiO}_{2}$ particles [21] and adopting novel methods [22], which is neither cost-efficient nor ecologically friendly.

In the present study, nano- $\mathrm{SiO}_{2}$ / potato starch films of different sizes $(15,30,80$, and $100 \mathrm{~nm})$ were synthesized by solution casting and characterized by X-ray diffraction, Fourier transform infrared spectroscopy, and scanning electron microscopy. The effects of gas permeability, water resistance, tensile strength, thermal stability, antibacterial properties, and preservation properties of the films on white mushrooms (Agaricus bisporus) were evaluated for their potential application as food packaging materials. To obtain the best properties, the optimal size of the nano- $\mathrm{SiO}_{2}$ particle was determined. This study guides the selection of the appropriate size of nano- $\mathrm{SiO}_{2}$ used directly in films to reduce processing costs or to combine with a dispersive method in order to improve the properties of the films.

\section{Materials and Methods}

\subsection{Materials}

Nano-SiO 2 (15, 30, 80, and $100 \mathrm{~nm})$ was purchased from Beijing Obo Biotechnology Co., Ltd. (Beijing, China). Potato starch was obtained from Beijing Aoboxing Bio-tech Co., Ltd. (Beijing, China). Gram-negative Escherichia coli (E. coli, CMCC[B]44102), and Gram-positive Staphylococcus aureus (S. aureus, CMCC[B]26003) were the selected bacterial strains. White mushrooms were harvested in Dezhou, China. Prior to package testing, mushrooms with uniform characteristics (size, shape, and color) were selected as the experimental materials.

\subsection{Starch Ultrasonication}

The moisture and $\mathrm{pH}$ of the starch were $20 \%$ and $4.5-7.0$ before ultrasonic treatment. The potato starch is composed of $80 \%$ large macromolecules of branched amylopectin and $20 \%$ amylose. The starch was sonicated (Frequency $20 \mathrm{kHz}$, Power $150 \mathrm{~W}$ ) for $20 \mathrm{~min}$ with a VCX 750 ultrasonic processor 
(VCX 750, Sonics, Newtown, CT, USA) and then dried at $45^{\circ} \mathrm{C}$ for $12 \mathrm{~h}$. They were grinded and sifted out to prepare the films.

\subsection{Preparation of $\mathrm{Nano}-\mathrm{SiO}_{2} /$ Potato Starch Films}

Pure potato starch films and potato starch/nano-SiO ${ }_{2}$ films were prepared by solvent casting. The process is illustrated in Figure 1. Prior to the preparation of nano- $\mathrm{SiO}_{2}$ solutions, $0.3 \%(w / v$ of water) nano- $\mathrm{SiO}_{2}$ of different sizes $(15,30,80$, and $100 \mathrm{~nm})$ was added to $300 \mathrm{~mL}$ distilled water and then sonicated for $20 \mathrm{~min}$ to obtain a homogenous suspension. Subsequently, $5 \%$ ( $w / v$ of water) of potato starch and $5 \%(w / v$ of water) glycerin were added while the mixture was being shaken and gelatinized under $80^{\circ} \mathrm{C}$ for $30 \mathrm{~min}$ The solution was allowed to cool down for degasification. Up to $100 \mathrm{~mL}$ of the solution was cast on a plastic utensil with a surface area measuring $25 \mathrm{~cm} \times 25 \mathrm{~cm}$ and then dried in a vacuum oven at $50{ }^{\circ} \mathrm{C}$. All uncovered samples were ultimately pretreated at $23^{\circ} \mathrm{C}$ and $50 \%$ relative humidity $(\mathrm{RH})$ in a humidity chamber for $24 \mathrm{~h}$ for the subsequent testing.

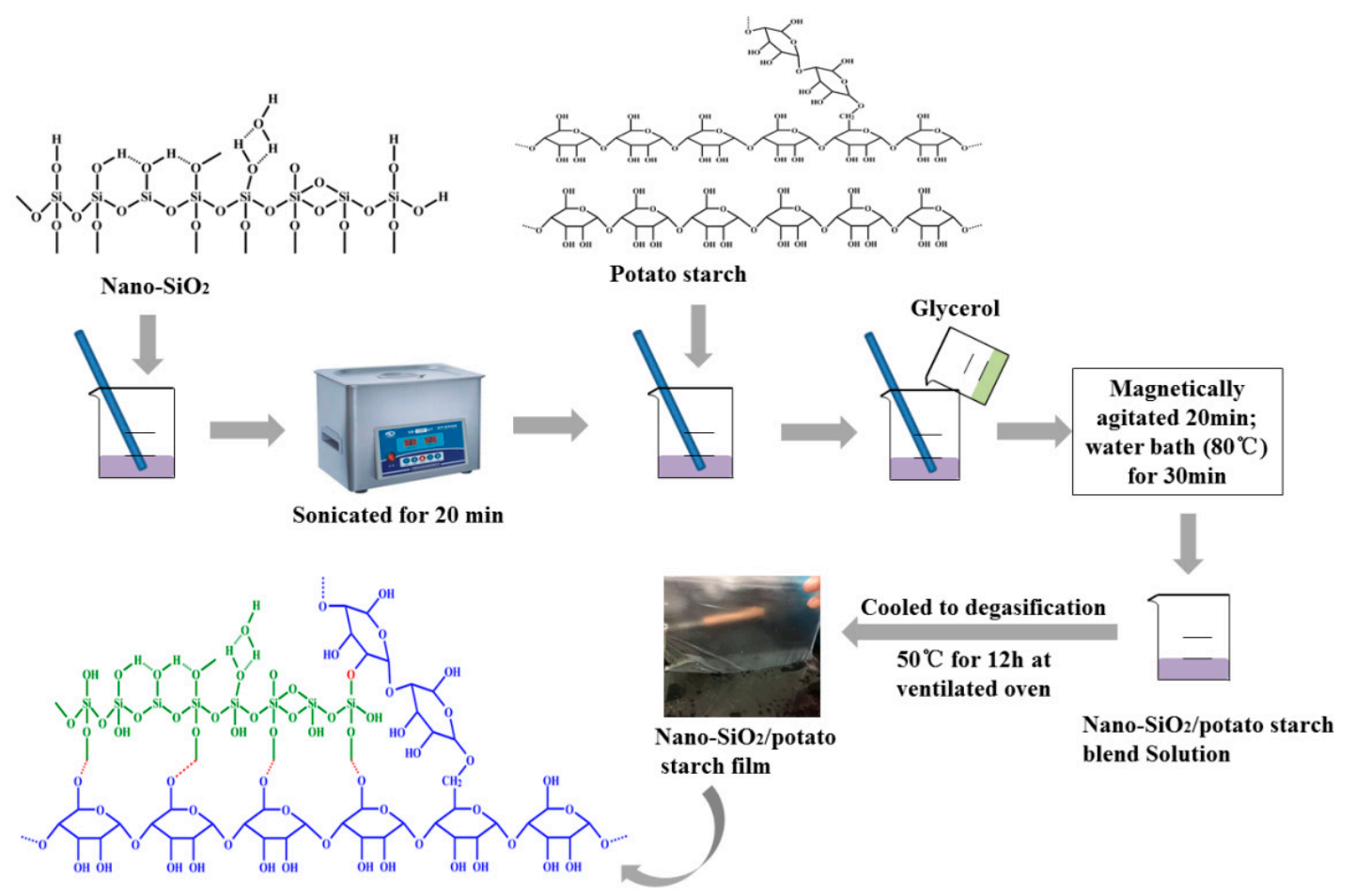

Figure 1. Schematic of the preparation of different films.

\subsection{Physical Properties of the Films}

\subsubsection{Water Vapor Transmission Rate}

Water vapor transmission rate (WVTR) was measured gravimetrically in accordance with Chinese National Standards GB1037-88 (1998). The films were covered on the top of the weighing bottle containing $3 \mathrm{~g}$ anhydrous $\mathrm{CaCl}_{2}$ and then fixed with a rubber band. The weighing bottles were placed in a constant temperature and humidity chamber $\left(25^{\circ} \mathrm{C} \mathrm{RH} 90 \%\right)$ for $24 \mathrm{~h}$. WVTR was calculated as follows [23]:

$$
W V T R=\frac{m_{\mathrm{f}}-m_{\mathrm{i}}}{D \times S}
$$

where $m_{\mathrm{f}}$ is the weight of the final bottle, and $m_{\mathrm{i}}$ is the weight of the initial bottle, $D$ is the time, $S$ is the effective area of the films, $\mathrm{m}^{2}$. 
2.4.2. Thickness, Oxygen Transmission Rate (OTR), Carbon Dioxide Transmission Rate (CDTR) and Water Resistance of the Films

The thickness of the films was measured using a hand-held micrometer with a precision of $0.01 \mathrm{~mm}$ as the mean of measurements obtained at 10 random points. The OTR and CDTR were measured according to Wang et al. (2014) [24]. The method described by Moreno et al. (2017) [25] was modified to measure the solubility and moisture absorption of the films. Their specific methods were described in the supplementary material.

\subsection{Tensile Strength}

The films were cut into rectangular strips $(5 \mathrm{~cm} \times 2 \mathrm{~cm}$ ). A texture analyzer (TA-XT, Stable Micro Systems, UK) with the AMTG probe was used to determine the tensile strength of the films as an average of 6 measurements for each film. The initial distance of separation and speed were adjusted to $30 \mathrm{~mm}$ and $10 \mathrm{~mm} / \mathrm{s}$, respectively.

\subsection{Optical Property}

The transparency and light transmission of the films were measured using a ultraviolet visible spectrophotometer (UV-2550, Shimadzu International Trading Co., Ltd., Shanghai, China) by scanning the samples at wavelengths in the $200-800 \mathrm{~nm}$ range, with air as reference.

\subsection{Thermal Properties}

The thermal stability of the films was measured using a thermogravimetric analyzer (Netzsch STA449C, Selb, Germany). All films were scanned from 30 to $600{ }^{\circ} \mathrm{C}$ at a heating rate of $283.15 \mathrm{~K} / \mathrm{min}$ under high-purity nitrogen. About $7 \mathrm{mg}$ of each film was placed into a standard aluminum pan, with an empty pan used as the reference. Three replicates of each film were analyzed to ensure repeatability [26].

\subsection{Characterization}

\subsubsection{Scanning Electron Microscopy (SEM) of Native Starch and Films}

The morphology of the films and starch were observed by SEM using an FEI Sirion 200 field-emission scanning electron microscope (FEI Sirion 200, FEI Co., Ltd., Hillsboro, OR, USA) operated at a voltage of $20 \mathrm{kV}$. Prior to observation, the starch and films were mounted on a cylindrical microscope stub covered with a carbon strip and sputter-coated with gold.

\subsubsection{Fourier Transform Infrared Spectroscopy (FTIR)}

The chemical composition of the films was observed by FTIR (Nicolet 5700, Thermo Electron, Hampton, NH, USA) from 4000 to $600 \mathrm{~cm}^{-1}$ at a scanning rate of $4 \mathrm{~cm}^{-1}$. The samples were fixed directly in the sample holder and evaluated.

\subsubsection{X-ray Diffraction (XRD)}

Diffraction patterns of the films were measured with an X-ray diffractometer (Bruker AXS Advance D8, Karlsruhe, Germany) coupled with Ni-filtered $\mathrm{Cu}$ and $\mathrm{K} \alpha$ radiation (accelerating voltage, $40 \mathrm{kV}$; current, $30 \mathrm{~mA}$ ). The scattering angle range was set to $5^{\circ}-45^{\circ}$ following a scan rate of $1^{\circ} / \mathrm{min}$.

\subsection{Antibacterial Property}

\subsubsection{Scanning Electron Microscope Assay}

The bacterial cells were incubated in a Luria-Bertani (LB) medium (Peptone $10 \mathrm{~g} / \mathrm{L}$, Yeast extract $5 \mathrm{~g} / \mathrm{L}, \mathrm{NaCl} 10 \mathrm{~g} / \mathrm{L}$, Agar $20 \mathrm{~g} / \mathrm{L}$ ) at $37^{\circ} \mathrm{C}$ overnight and then adjusted to $0.5-1$ McFarland standards. 
The bacteria cells were then treated with nano- $\mathrm{SiO}_{2}$ suspension $(0.3 \%, w / v$ of water) at different sizes for $2 \mathrm{~h}$ after the suspensions were centrifuged at $1500 \mathrm{~g}$ for $10 \mathrm{~min}$. A $0.1 \mathrm{M}$ phosphate buffer solution (PBS, pH 7.4) was used to wash the precipitated cells twice. Subsequently, $5 \%$ glutaraldehyde was employed to fix E. coli and S. aureus for $4 \mathrm{~h}$ under dark conditions. All samples were washed with PBS thrice and then dehydrated in various ethanol solutions. The treated E. coli and S. aureus were covered with gold by cathodic spraying. SEM (FEI Sirion 200, FEI Co., Ltd., Hillsboro, OR, USA) was ultimately used to observe the morphological changes in the bacterial cells.

\subsubsection{Agar Disk Diffusion Assay}

The films were cut into a disc shape with a $6 \mathrm{~mm}$ diameter and then sterilized with $75 \%$ alcohol solution. They were preloaded on seeded agar plates, incubated at $37^{\circ} \mathrm{C}$ for $24 \mathrm{~h}$. Subsequently, the inhibitions against E. coli and S. aureus were measured as the diameters of the zones of inhibition around the films [27].

\subsection{Preservation Property}

White mushrooms (A. bisporus) were placed in $1050 \mathrm{~mL}$ polypropylene trays $(14.0 \mathrm{~cm} \times 8.50 \mathrm{~cm}$ $\times 6.80 \mathrm{~cm}$ ). The polypropylene trays were tightly covered with nano- $\mathrm{SiO}_{2} /$ potato starch films with nano-SiO${ }_{2}$ of different sizes and then fixed with a rubber band. No-film packaging was used as the control. Each treatment was performed using 20 trays, with each tray containing about $160 \mathrm{~g}$ of white mushrooms. The weight loss, membrane permeability, hardness, surface color $\Delta E$, and flesh color $\Delta E$ of white mushrooms were measured at intervals $(0,3,6,9$, and $12 \mathrm{~d})$ during storage at $4{ }^{\circ} \mathrm{C}$.

Weight loss was determined by weighing the mushrooms before and during the storage period. The color (surface $\Delta E$ and flesh $\Delta E$ ) was measured with a colorimeter (SC-80C, Kangguang Instrument Co., Ltd., Beijing, China). The hardness was measured with a GY-1 penetrometer (Mudanjiang Machinery Research Institute, Mudanjiang, China). The cell membrane permeability was expressed by tissue electrolyte leakage. Electrolyte leakage was measured following a procedure from Liu et al. (2010) [28]. The measurement was performed three times.

\subsection{Statistical Analysis}

The properties of the nano-SiO $2 /$ potato starch films with nano-SiO $\mathrm{S}_{2}$ of different sizes were presented as means \pm standard deviation at least in duplicates. All statistical analyses were performed using SPSS ver. 20 (SPSS Inc., Chicago, IL, USA) to analyze the variance. Duncan's multiple-range test $(p<0.05)$ was employed to compare the differences.

\section{Results and Discussion}

\subsection{SEM Analysis}

The surface morphology of films ultimately could reveal many properties of biodegradable materials. Figure 2 describes the microscopy of surface changes in the starch and nano- $\mathrm{SiO}_{2} /$ potato starch films. The native potato starch was not uniform in shape and size, and the surface was flat and smooth. After ultrasonication, starch particles had rough surfaces with some spherical bulge, which formed by the aggregation of submicrocrystals and crystals. The dispersion of nanoparticle in the hosting matrix was associated with the macroscopic properties of the films [29]. Homogeneous dispersion of nanoparticles was necessary to successfully enhance the barrier properties of the films. As observed, the surface of the potato starch-based blend film without nano- $\mathrm{SiO}_{2}$ was smooth and homogenous, whereas that of the film with nano- $\mathrm{SiO}_{2}$ was rough. Moreover, $15 \mathrm{~nm}$ nano- $\mathrm{SiO}_{2}$ formed large aggregates, whereas those with increasing size showed less aggregation. The reason could be that the smaller particles had higher specific surface areas to form aggregates easily. This agglomeration could cause the large areas of the material to remain free from nanoparticles that influence the 
properties of the films. Therefore, the $100 \mathrm{~nm}$ nano- $\mathrm{SiO}_{2} /$ potato starch films would exhibit the best barrier properties. This hypothesis will be discussed in a later section.

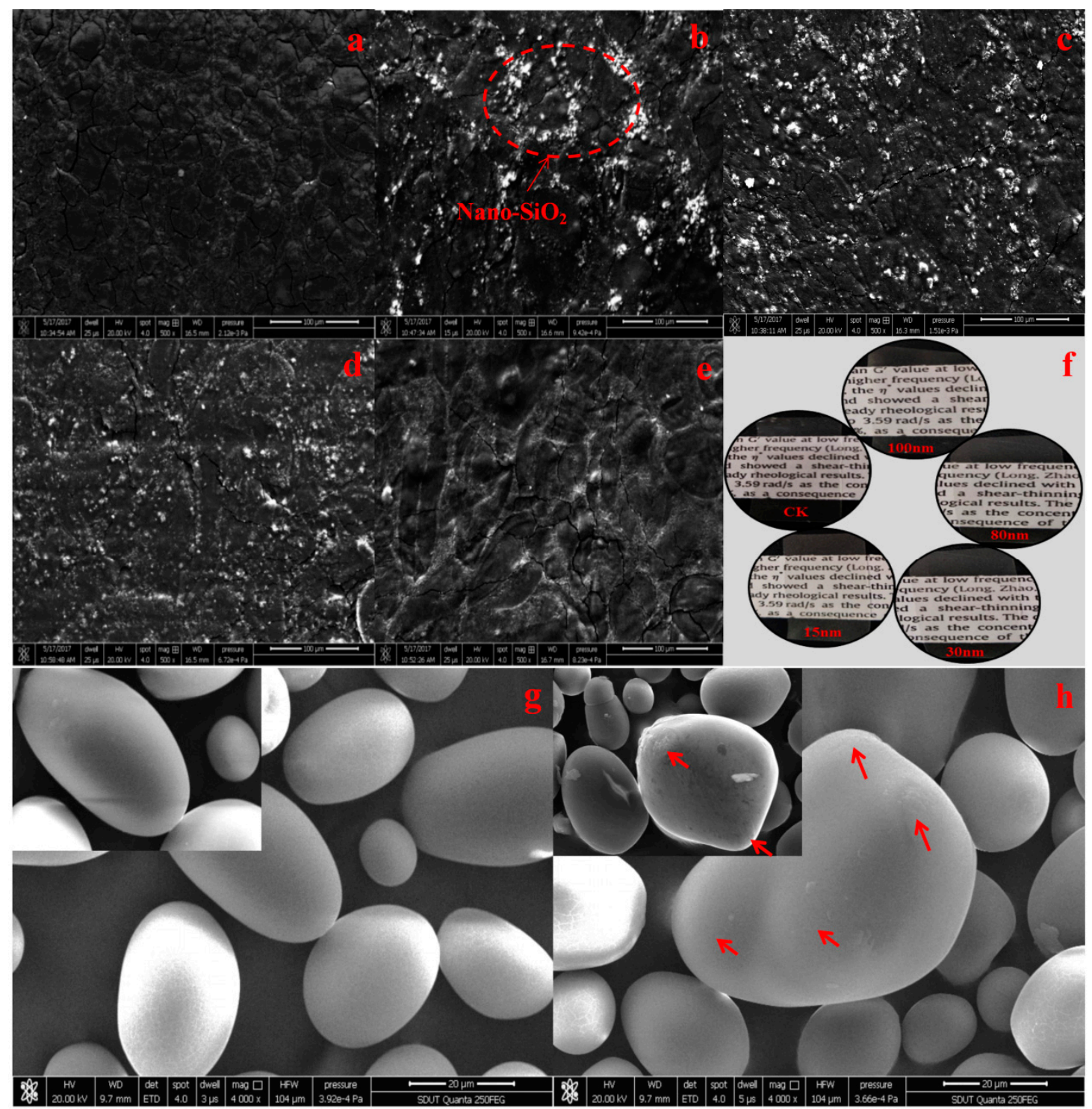

Figure 2. SEM and apparent images of starch and nano- $\mathrm{SiO}_{2}$ / potato starch films. (a) CK: films without nano- $\mathrm{SiO}_{2}$; (b) films with the $15 \mathrm{~nm}$ nano- $\mathrm{SiO}_{2}$; (c) films with the $30 \mathrm{~nm}$ nano- $-\mathrm{SiO}_{2}$; (d) films with the $80 \mathrm{~nm}$ nano- $\mathrm{SiO}_{2} ;$ (e) films with the $100 \mathrm{~nm}$ nano- $\mathrm{SiO}_{2} ;$ (f) the apparent images of different films (g) native potato starch; (h) potato starch after ultrasonication.

\subsection{XRD Analysis}

XRD can characterize the compatibility of films. When the crystalline and non-crystalline ingredients in the films exhibit good miscibility, the crystallinity becomes lower than that of the single-crystalline ingredient [30]. The XRD of nano- $\mathrm{SiO}_{2}$ / potato starch films was presented in Figure 3. The characteristic diffraction peak of the potato starch films without nano- $\mathrm{SiO}_{2}$ appeared clearly at around $20^{\circ}$, which could be attributed to the crystalline and amorphous fractions of the potato starch [31]. Comparison of the patterns with the addition of nano- $\mathrm{SiO}_{2}$ indicated that the diffraction peak weakened with an increase in size. The intermolecular interactions between potato starch and nano- $\mathrm{SiO}_{2}$ led to the dispersion of the nano- $\mathrm{SiO}_{2}$ molecules into the potato starch matrix. Meanwhile, nano- $\mathrm{SiO}_{2}$ destroyed the original crystalline domains of the potato starch films to decrease the crystallinity. In addition, nano- $\mathrm{SiO}_{2}$ of a smaller particle size and a larger surface was easier to 
reunite. Thus, the $100 \mathrm{~nm}$ nano- $\mathrm{SiO}_{2}$ could be more easily dispersed in the potato starch films and disrupt the regularity of the arrangement among the potato starch and nano- $\mathrm{SiO}_{2}$ molecules, thereby decreasing the crystallinity of nano- $\mathrm{SiO}_{2} /$ potato starch films. The results supported the conclusion drawn from SEM that potato starch and nano- $\mathrm{SiO}_{2}$ exhibited good compatibility and that optimal dispersibility was obtained with the $100 \mathrm{~nm}$ nano- $-\mathrm{SiO}_{2}$.

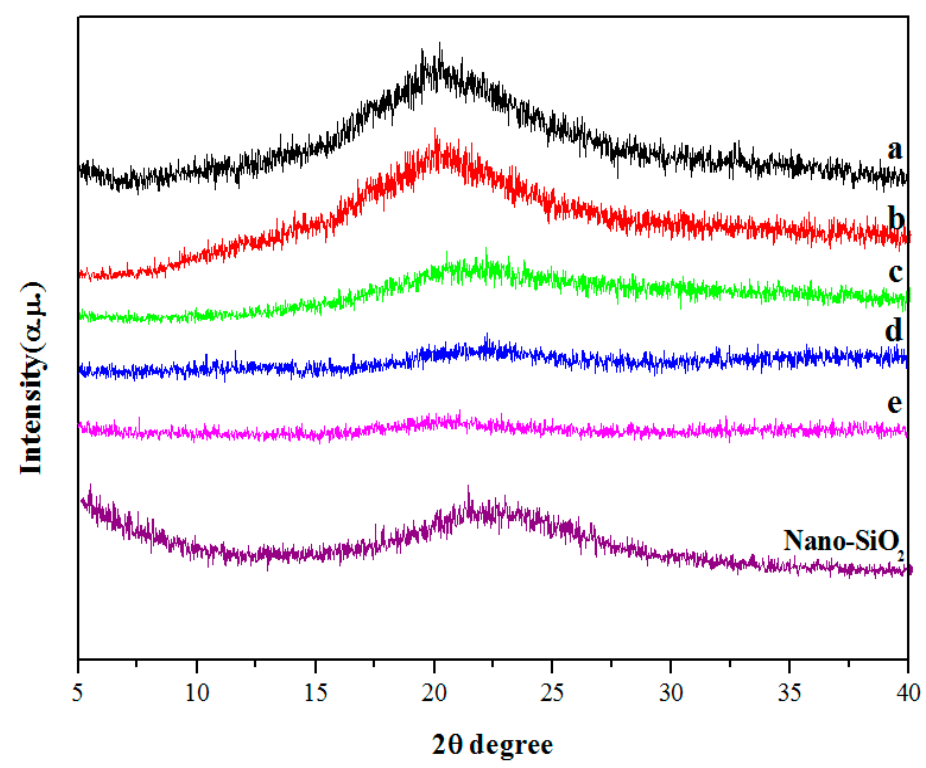

Figure 3. XRD patterns of the potato starch films with different size of nano-SiO 2 . (a) $\mathrm{CK}$ : films withoutnano- $\mathrm{SiO}_{2}$; (b) films with the $15 \mathrm{~nm}$ nano- $\mathrm{SiO}_{2}$; (c) films with the $30 \mathrm{~nm}$ nano-SiO 2 ; (d) films with the $80 \mathrm{~nm}$ nano- $\mathrm{SiO}_{2}$; (e) films with the $100 \mathrm{~nm}$ nano- $\mathrm{SiO}_{2}$.

\subsection{FTIR Analysis}

FTIR spectroscopy as a powerful technique can determine the miscibility of polymers. The detailed chemical bond structures of the films at $4000-400 \mathrm{~cm}^{-1}$ were presented in Figure 4 . A strong and broad adsorption band appeared at $3340 \mathrm{~cm}^{-1}$ because of the $-\mathrm{OH}$ groups on the potato starch backbone. The $\mathrm{H}-\mathrm{O}-\mathrm{H}$ stretching vibration absorption appeared at $1650 \mathrm{~cm}^{-1}$, and the peak at $2936 \mathrm{~cm}^{-1}$ was ascribed to the $\mathrm{C}-\mathrm{H}$ stretching vibration [32]. The peaks at about 928, 992, and $1025 \mathrm{~cm}^{-1}$ represented the $\mathrm{C}-\mathrm{O}-\mathrm{C}$ stretching vibration in the starch structure. With the nano- $\mathrm{SiO}_{2}$ of different sizes added, the strong absorption band widened at $3340 \mathrm{~cm}^{-1}$ and was then transferred to the low wavenumbers. The $100 \mathrm{~nm}$ nano- $\mathrm{SiO}_{2}$ became dominant and shifted to $3335 \mathrm{~cm}^{-1}$. In addition, the peak at $2936 \mathrm{~cm}^{-1}$ moved to $2933 \mathrm{~cm}^{-1}$. The peaks at $1025 \mathrm{~cm}^{-1}$ were also transferred to the low wavenumbers, indicating that the active group of potato starch formed the hydrogen bond with $-\mathrm{OH}$ on the nano-SiO${ }_{2}$ surface. The peaks at 1260 and $987 \mathrm{~cm}^{-1}$ were attributed to the $\mathrm{Si}-\mathrm{C}$ stretching vibration and bending vibration [33], the peaks at 1072 and $922 \mathrm{~cm}^{-1}$ were attributed to the $\mathrm{Si}-\mathrm{O}$ stretching vibration and $\mathrm{Si}-\mathrm{H}$ bending vibration. It indicated that the intermolecular hydrogen bonding between nano- $\mathrm{SiO}_{2}$ and potato starch increased. The FTIR results confirmed that the compatibility between nano- $\mathrm{SiO}_{2}$ and potato starch was attributed to intermolecular hydrogen bonding, and the $100 \mathrm{~nm}$ nano- $\mathrm{SiO}_{2}$ could be dispersed most uniformly during film formation and blending [22]. The finding was consistent with the SEM and XRD results, indicating that the $100 \mathrm{~nm}$ nano- $\mathrm{SiO}_{2}$ exhibited good miscibility. 


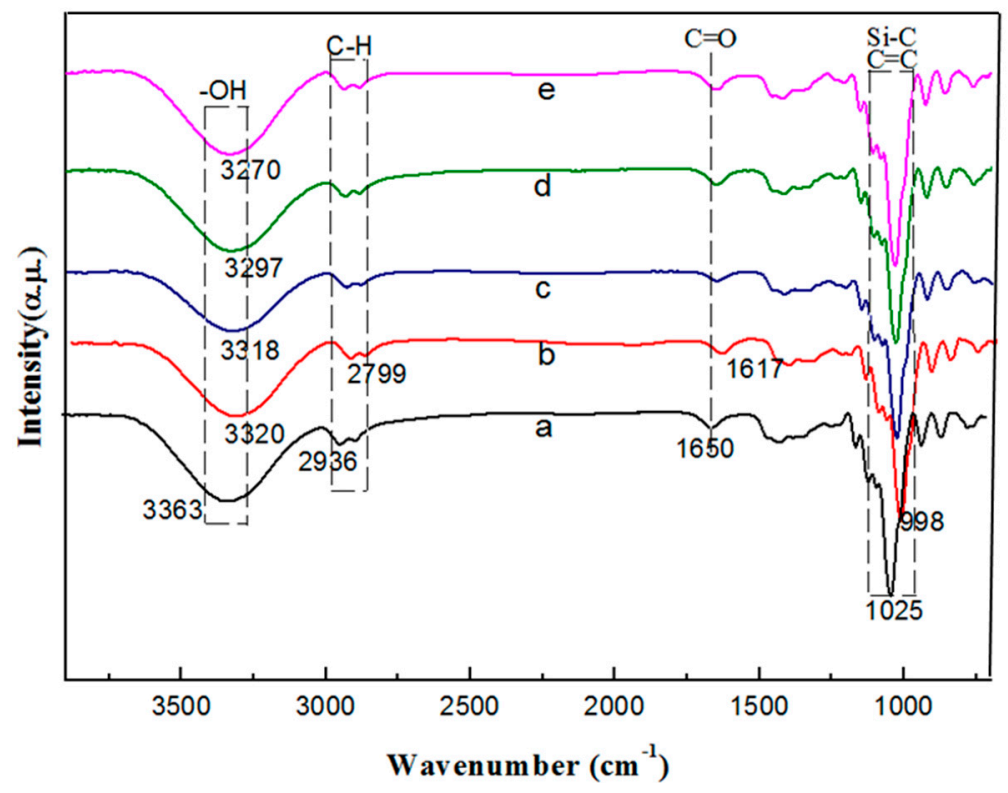

Figure 4. FTIR of the films with nano-SiO 2 of different sizes. (a) $\mathrm{CK}$ : films withoutnano- $\mathrm{SiO}_{2}$; (b) films with the $15 \mathrm{~nm}$ nano- $\mathrm{SiO}_{2}$; (c) films with the $30 \mathrm{~nm}$ nano-SiO (e) films with the $100 \mathrm{~nm}$ nano- $\mathrm{SiO}_{2}$.

\subsection{TG and DTG Analysis}

The thermal stability of the films was determined by TG and DTG. The weight loss thermograms of the films were shown in Figure 5. Three well-defined stages represent the weight loss of all films in the following ranges: (i) $100-200{ }^{\circ} \mathrm{C}$, (ii) $200-330^{\circ} \mathrm{C}$, and (iii) $330-600{ }^{\circ} \mathrm{C}$. The first stage showed a small weight loss (about $10 \%$ ) that was attributed to moisture from the surface or interior of the films. The decomposition rate of the nano- $\mathrm{SiO}_{2}$ / potato starch films was lower than that of the potato starch films. This difference indicated that the motion and reaction of water molecules were hindered with the addition of nano- $\mathrm{SiO}_{2}$ [34]. The second stage demonstrated the thermal expansion of films with a weight loss of $60 \%-70 \%$. This occurrence was attributed to the loss of the adjacent hydroxyl group and cleavage of the glycosidic bond [9]. Compared with that of the pure potato starch films, the weight loss decreased in the range of $270-330^{\circ} \mathrm{C}$ with the addition of nano- $\mathrm{SiO}_{2}$ because of the strong interaction between the nano- $\mathrm{SiO}_{2}$ and potato starch. The potato starch films had a weight loss of $70.1 \%$ from 200 to $330{ }^{\circ} \mathrm{C}$, whereas the nano-SiO 2 / potato starch films $(15,30,80$, and 100) had weight losses of $67.4 \%$, $66.0 \%, 65.4 \%$, and $60.5 \%$, respectively, at the same temperature. These losses demonstrated that strong interactions between starch molecules and $\mathrm{Si}-\mathrm{OH}$ in nano- $\mathrm{SiO}_{2}$ delayed the movement of the molecular chains to strengthen the thermostability of the films $[35,36]$. These results were consistent with the results of FTIR. The third stage showed the weight loss was in ceases, indicating that such behavior was related to the crystallinity of the films when dissolved nano- $\mathrm{SiO}_{2}$ was dispersed in the matrix of the potato starch films. The result was identified in the XRD pattern. The amount of residue in the films with nano- $\mathrm{SiO}_{2}$ of different sizes followed the order $100 \mathrm{~nm}>80 \mathrm{~nm}>30 \mathrm{~nm}>15 \mathrm{~nm}$. The results indicated that the $100 \mathrm{~nm}$ nano- $\mathrm{SiO}_{2}$ / potato starch films exhibited the highest thermostability because nano- $\mathrm{SiO}_{2}$ was more homogeneous in the films. 


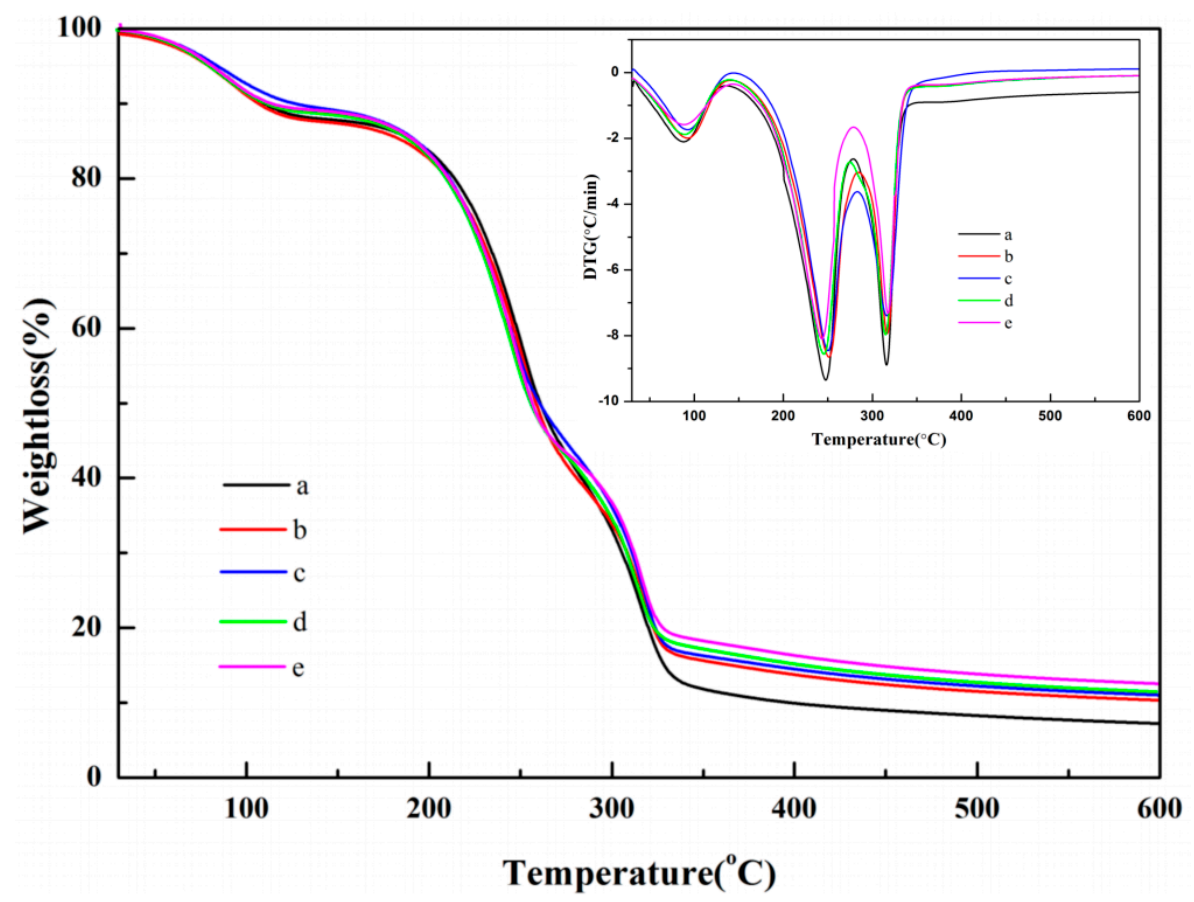

Figure 5. TG and DTG curves of the films. (a) CK: films withoutnano- $\mathrm{SiO}_{2} ;$ (b) films with the $15 \mathrm{~nm}$ nano- $\mathrm{SiO}_{2}$; (c) films with the $30 \mathrm{~nm}$ nano-SiO 2 ; (d) films with the $80 \mathrm{~nm}$ nano-SiO 2 ; (e) films with the $100 \mathrm{~nm}$ nano- $\mathrm{SiO}_{2}$.

\subsection{Physical and Mechanical Properties of the Films}

\subsubsection{Water Vapor Transmission Rate Analysis}

The WVTR could represent moisture transport through films. This measurement was a key factor for maintaining the good quality of food against water adsorption and desorption in food packaging [37]. The WVTRs of nano-SiO 2 / potato starch films with different sizes are given in Figure 6a. The WVTRs of the films decreased because of the increase in nano-SiO ${ }_{2}$ size. The SEM image (Figure 1) of the films showed compact structures when nano- $\mathrm{SiO}_{2}$ particles with different sizes were added. The phenomenon was ascribed to the hydrogen bonds between the oxygen atoms of nano- $\mathrm{SiO}_{2}$ and potato starch matrix. In addition, the good dispersion of nano- $\mathrm{SiO}_{2}$ in the potato starch matrix provided curving paths for water molecules to across the films [38]. In a previous study, the WVTR was also affected by the degree of crystallinity, size of the nano-particles, free volume, and macro-voids [39]. The $100 \mathrm{~nm}$ nano- $\mathrm{SiO}_{2} /$ potato starch films obtained the lowest WVTR $\left(789.41 \mathrm{~g} / \mathrm{m}^{2} \cdot \mathrm{d}\right)$, which was ascribed to the decrease in crystallinity of the $100 \mathrm{~nm}$ nano- $\mathrm{SiO}_{2}$ to a greater extent (Figure 2). The small size of nano- $\mathrm{SiO}_{2}$ was found to facilitate the dispersion in the films, resulting in a low WVTR [40].

\subsubsection{Tensile Strength Analysis}

The tensile strengths $\left(T_{\mathrm{s}}\right)$ of the films with nano-SiO${ }_{2}$ of different sizes were given in Figure $6 \mathrm{~b}$. The control potato starch films exhibited a lower tensile strength $(15.1 \mathrm{MPa})$ than that of the nano- $\mathrm{SiO}_{2}$ / potato starch films. The incorporation of the nano- $\mathrm{SiO}_{2}$ significantly affected the tensile strength of the potato starch films. The matrix of the potato starch films could be strengthened by $\mathrm{O}-\mathrm{Si}-\mathrm{O}$ bonding, hydrogen bonding, or electrostatic attraction with the incorporation of nano- $\mathrm{SiO}_{2}[41]$. The optimal tensile strength was obtained when the $100 \mathrm{~nm}$ nano- $\mathrm{SiO}_{2}$ was used. The $100 \mathrm{~nm}$ nano- $\mathrm{SiO}_{2}$ was well adsorbed and bonded with potato starch in the formation of the films, thus improving the interphase adhesion strength between the matrix and the nano- $\mathrm{SiO}_{2}$. In addition, the smaller nano- $\mathrm{SiO}_{2}$ was more prone to agglomeration in the dispersion, indicating that their high surface energy led to the aggregation of nano- $\mathrm{SiO}_{2}$ and destroyed the original integrity of the films [37]. This finding agreed 
with the SEM results. This reinforcing effect of nano-SiO ${ }_{2}$ was consistent with the previous study by Jiang et al. (2016) [35].

\subsubsection{Optical Property Analysis}

The spectroscopic images of the films with nano- $\mathrm{SiO}_{2}$ of different sizes from 200 to $800 \mathrm{~nm}$ were presented in Figure 6c. The transmittance of the films gradually increased as the wavelength increased. The addition of nano- $\mathrm{SiO}_{2}$ caused low transmittance, indicating that the nano- $\mathrm{SiO}_{2} /$ potato starch films could resist against UV light, restraining the deterioration of food caused by UV radiation [42]. Notably, the UV light barrier values presented in this study for the nano- $\mathrm{SiO}_{2}$ / potato starch films prepared using $100 \mathrm{~nm}$ nano-SiO 2 were higher than those other films. Only 30\% UV light could pass through the $100 \mathrm{~nm}$ films at $600 \mathrm{~nm}$. The result indicated that the $100 \mathrm{~nm}$ nano- $\mathrm{SiO}_{2}$ could be uniformly distributed in the potato starch matrix. The size of nano- $\mathrm{SiO}_{2}$ could affect the transmittance of the films, which was consistent with the findings of Hassannia-Kolaee et al. (2016) [23].
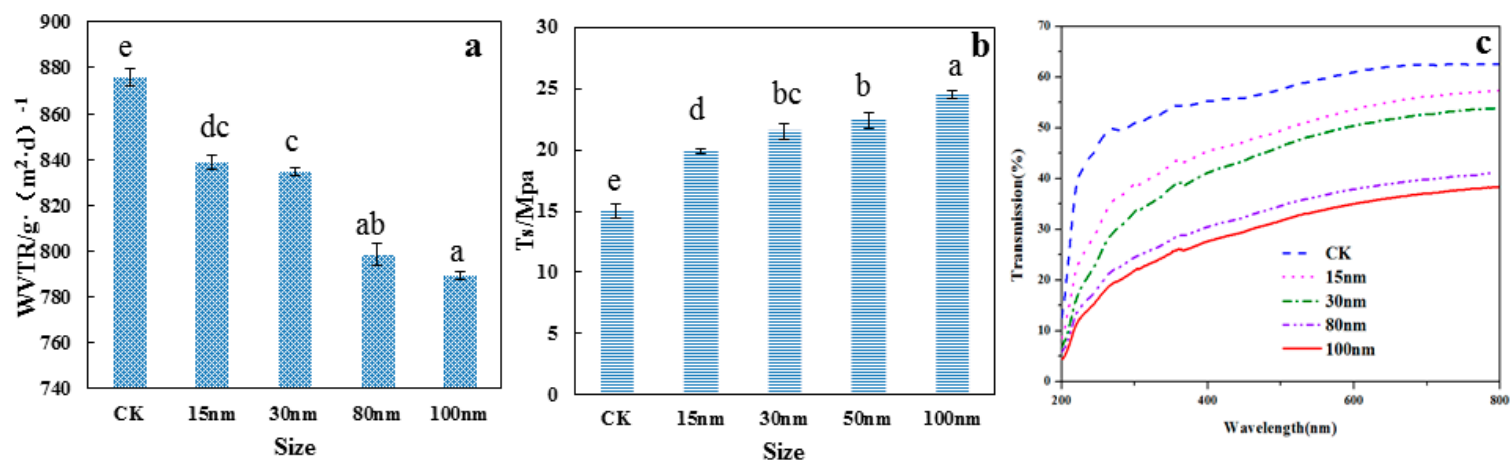

Figure 6. The WVTR (a), $T_{\mathrm{s}}(\mathbf{b})$, and transparency (c) of the potato starch films with nano-SiO ${ }_{2}$ of different sizes.

\subsubsection{Thickness}

The thickness of the films with nano- $\mathrm{SiO}_{2}$ of different sizes is presented in Figure S1a (Supplementary Materials). The thicknesses of the films ranged from 0.087 to $0.091 \mathrm{~mm}$. No significant difference was observed between the different films $(p>0.05)$. Many studies reported that film thickness could affect the properties of the films [43]. This finding showed that the thicknesses of the films with nano-SiO ${ }_{2}$ of different sizes in the present study showed no significant difference to accurately investigate their properties.

\subsubsection{CDTR and OTR Analysis}

Many degradation reactions in foods occur because of oxygen, which changes the nutritional and sensory value of food, shortening their shelf life. Oxidation mainly led to these reactions, such as vitamins loss, enzymatic browning, and fat rancidity. Therefore, the functions of packaging materials for reducing the deteriorative effects of oxygen were of great concern [44]. The starch films had the advantage of a lower OTR than that of synthetic films [45]. Figure S1b,c (Supplementary Materials) showed that the gas transmission rate (OTR and CDTR) decrease with the addition of nano- $\mathrm{SiO}_{2}$. During packaging, $\mathrm{O}_{2}$ and $\mathrm{CO}_{2}$ would first dissolve on the high-pressure side of the films. The difference in pressure could cause the gas molecules to be stuck in the torque hole, leading to a violent movement of the macromolecular chains of the films. $\mathrm{O}_{2}$ and $\mathrm{CO}_{2}$ would gradually penetrate along this channel and finally be released from the side with low partial pressure [8]. This occurrence indicated that dispersed nano- $\mathrm{SiO}_{2}$ changed the micropore structure of the potato starch films and that the $\mathrm{Si}-\mathrm{O}-\mathrm{Si}$ groups in the films could control the exchange of $\mathrm{O}_{2}$ and $\mathrm{CO}_{2}$. Meanwhile, OTR and CDTR decreased with an increase in nano-SiO ${ }_{2}$ size. The OTR and CDTR of the $100 \mathrm{~nm}$ films were $111.54 \mathrm{~g} / \mathrm{m}^{2} \cdot \mathrm{d}$ and $902.47 \mathrm{~g} / \mathrm{m}^{2} \cdot \mathrm{d}$, respectively, which could inhibit the respiration of fruits and 
vegetables in the package. The reason might be that the nano-SiO${ }_{2}$ particles with a smaller size and a larger surface area were severely agglomerated to reduce hydrogen bonds, leading to the increased gas permeabilities of the films. Sun et al. also reported that the gas permeabilities decreased, which was caused by the dispersibility of the nano- $\mathrm{SiO}_{2}$.

\subsubsection{Water Resistance}

The effect of nano-SiO${ }_{2}$ size on the moisture absorption and solubility of the films is shown in Figure S1d,e (Supplementary Materials). The moisture absorption and solubility of the films were markedly decreased with an increase in size of the nano- $\mathrm{SiO}_{2}$. The intermolecular hydrogen bonds between nano- $\mathrm{SiO}_{2}$ and potato starch increased the cohesiveness of the film matrix by the formation of a network structure. Therefore, nano- $\mathrm{SiO}_{2}$ enhanced the moisture absorption and solubility of the films $[40,46]$. Furthermore, the100nm nano- $\mathrm{SiO}_{2}$ was uniformly distributed in the potato starch matrix, resulting in a good interaction between the nano- $\mathrm{SiO}_{2}$ and the potato starch. This effect indicated that the total void volume of the water molecules was reduced in the microstructures of the films. This result was consistent with SEM and FTIR. Consequently, the nano-SiO ${ }_{2} /$ potato starch films $(100 \mathrm{~nm})$ exhibited the optimal barrier and water resistance properties, which the moisture absorption $(18.4 \%)$ and solubility $(52.7 \%)$ were lower than other films.

\subsection{Antibacterial Property Analysis}

\subsubsection{Scanning Electron Microscopy}

Figure 7 described the SEM images of E. coli and S. aureus treated with nano- $\mathrm{SiO}_{2}$ of different sizes. The images illustrate the antibacterial activity of nano- $\mathrm{SiO}_{2}$ on the tested bacteria. Compared with those of the untreated controls, the morphological surfaces of the treated bacteria were markedly changed. The untreated E. coli appeared regular, rod-shaped, and intact (Figure 7a). The untreated S. aureus appeared intact and spherical (Figure 7f). Some of the E. coli treated with nano-SiO deformed, shriveled, pitted, adhered to each other, and parts of the cell were broken, which could lead to the leaching out of genetic materials and nutrients [35]. Moreover, the changes were more severe and evident with a decrease in nano- $\mathrm{SiO}_{2}$ size (Figure $7 \mathrm{~b}-\mathrm{e}$ ), indicating that the $15 \mathrm{~nm}$ nano- $\mathrm{SiO}_{2}$ showed an extremely porous structure and high surface activity following the sufficient adsorption properties [13]. Moreover, the boundaries of the bacteria were irregular and wrinkled. However, nano- $\mathrm{SiO}_{2}$ was less efficient against $S$. aureus (Figure $7 \mathrm{~g}-\mathrm{j}$ ). The difference could be explained by the structural difference in E. coli and S. aureus. Both bacteria exhibited resemblance in their internal structures, but now also in their external structures. The cells of E. coli had an outer membrane composed of proteins, phospholipids, and lipopolysaccharide, possessing a thin peptidoglycan layer. The cell of $S$. aureus possessed a thick peptidoglycan layer containing lipoteichoic acids and teichoic. Thus, higher concentrations of nano- $\mathrm{SiO}_{2}$ and longer contact time for $\mathrm{S}$. aureus would be required to obtain the same effect as that of E. coli [13]. Relevant investigations should be further conducted to clarify its mechanism. 

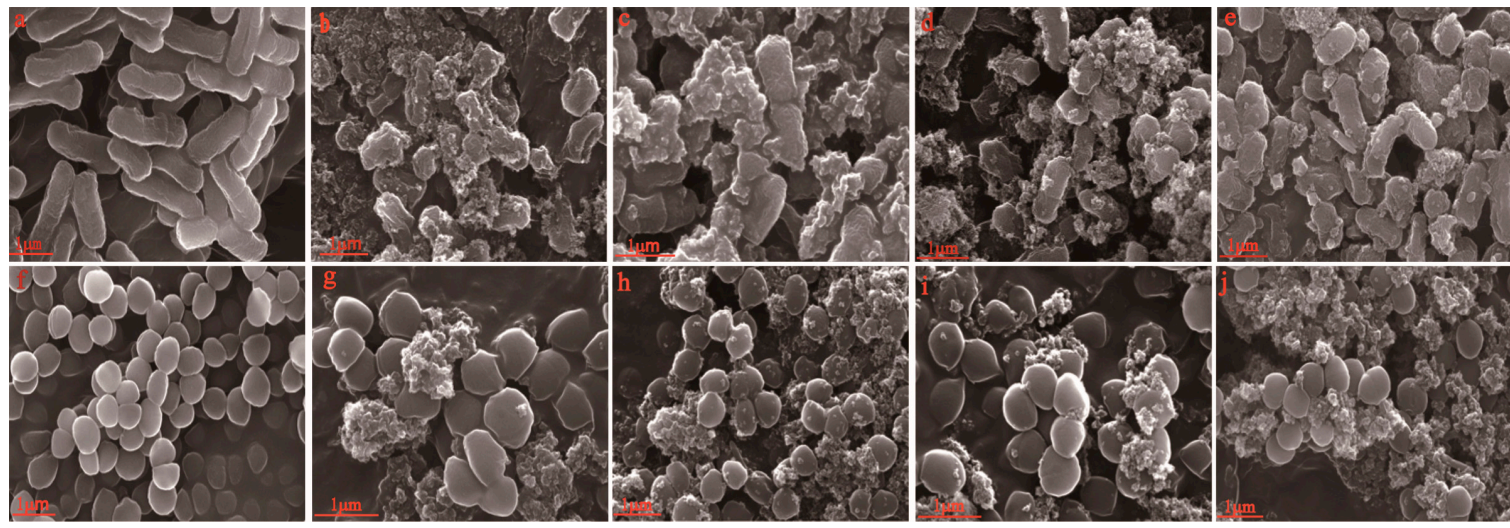

Figure 7. SEM of E. coli and S. aureus. (a) Image of untreated E. coli; (b), (c), (d), and (e) Images of E. coli treated with nano-SiO 2 particles measuring 5, 30, 80, and $100 \mathrm{~nm}$; (f) Image of untreated S. aureus; (g), $(\mathbf{h})$, (i), and (j) Images of E. coli and S. aureus treated with nano-SiO 2 particles measuring 15, 30, 80, and $100 \mathrm{~nm}$.

\subsubsection{Antibacterial Activity of the Films}

The films with nano-SiO $\mathrm{S}_{2}$ of different sizes for their antibacterial activity against $E$. coli and $S$. aureus are presented in Figure 8 and Table S1 (Supplementary Materials). The inhibitory effect was determined based on the clear zone around the film discs. The zones of inhibition around the films included the diameter of the film discs. This finding suggested the absence of antibacterial activity because no clear zone was observed around the films. All the nano- $\mathrm{SiO}_{2} /$ potato starch films were not infested with bacteria, indicating that external bacteria were prevented from passing through the films to infect food in the packaging process. The nano- $\mathrm{SiO}_{2} /$ potato starch films showed a significant inhibitory effect against $E$. coli and low efficiency against $S$. aureus. The nano- $\mathrm{SiO}_{2}$ could be adsorbed on the cell walls of the bacteria, destroying the structure of the cell membranes. The structure of the cell organelles was then destroyed because of the permeation of the nano- $\mathrm{SiO}_{2}$. Thus, nano- $\mathrm{SiO}_{2}$ could damage the antioxidant system and produce stronger lipid peroxidation. In addition, the inhibitory zone of the films with $15 \mathrm{~nm}$ nano- $\mathrm{SiO}_{2}$ measured $1.2 \mathrm{~cm}$. However, part of the films with $15 \mathrm{~nm}$ nano- $\mathrm{SiO}_{2}$ had no inhibitory zone because of the aggregation of $15 \mathrm{~nm}$ nano- $-\mathrm{SiO}_{2}$ in the potato starch films. The inhibitory zone of the films with $100 \mathrm{~nm}$ nano- $\mathrm{SiO}_{2}$ measured $0.8 \mathrm{~cm}$, and all samples had inhibitory zones. This finding indicated that the films with $100 \mathrm{~nm}$ nano- $\mathrm{SiO}_{2}$ exhibited a higher antibacterial activity. Therefore, the uniform dispersion of the nano- $\mathrm{SiO}_{2}$ with small particles in the potato starch films plays a crucial role in fruit and vegetable preservation.

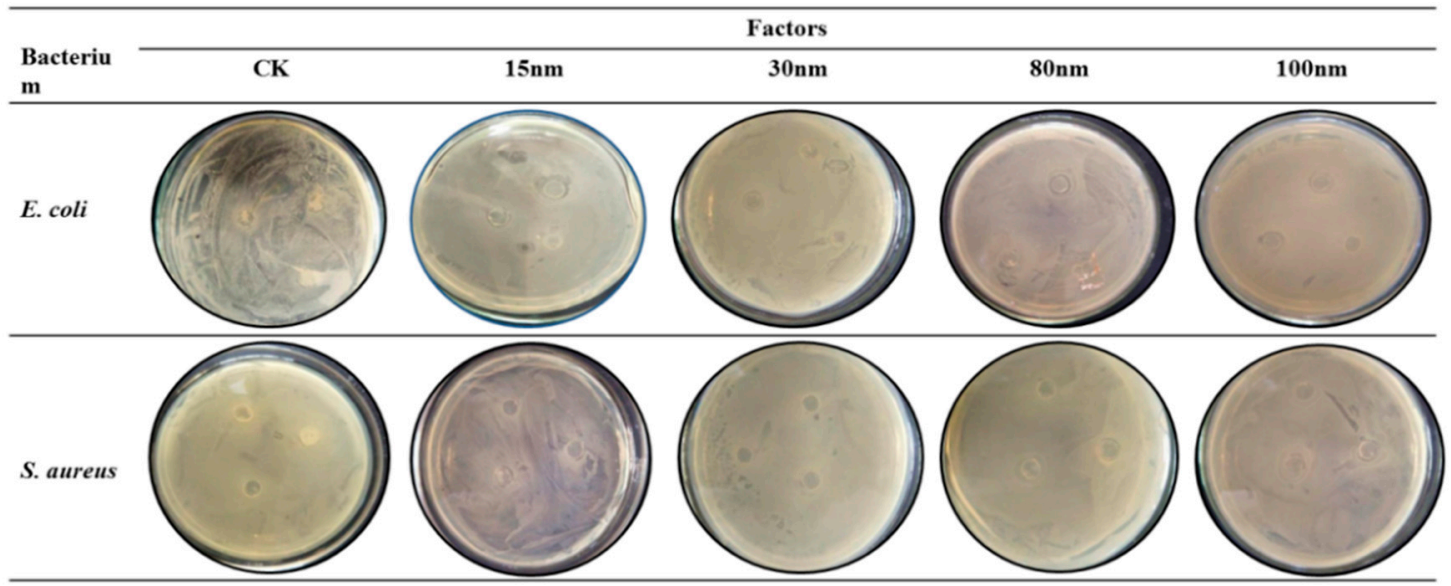

Figure 8. Inhibitory effect of potato starch films with nano- $\mathrm{SiO}_{2}$ of different sizes against $E$. coli and S. aureus. 


\subsection{Preservation Properties of the Films on White Mushrooms (A. Bisporus)}

To determine the change in the quality of white mushrooms packaged in nano- $\mathrm{SiO}_{2} /$ potato starch films during storage, the weight loss, membrane permeability, hardness, and color were evaluated (Figure 9). After the postharvest of white mushrooms, the weight loss, membrane permeability, hardness, and color deteriorated because of high metabolic activity, respiration rate, and dehydration. The results indicated that membrane permeability, hardness, and color of white mushrooms decreased, and weight loss increased with storage. Meanwhile, all quality indices changed slowly with the potato starch/nano-SiO ${ }_{2}$ films. Moreover, the nano- $\mathrm{SiO}_{2}$ / potato starch films exhibited better storage and preservation properties (Figure S1, Supplementary Materials) as the size of the nano-SiO $\mathrm{increased}_{\text {. }}$ The $100 \mathrm{~nm}$ nano- $\mathrm{SiO}_{2}$ was uniformly dispersed in the potato starch films and combined with potato starch by hydrogen and chemical bonding. Therefore, the $100 \mathrm{~nm}$ nano- $\mathrm{SiO}_{2}$ /potato starch films in the package could reduce the permeation of gas and water, as well as inhibit the growth of microorganism, strengthen the mechanical properties, and improve the microstructures of the films. This enhancement delayed the change in the quality of white mushrooms within the storage period.
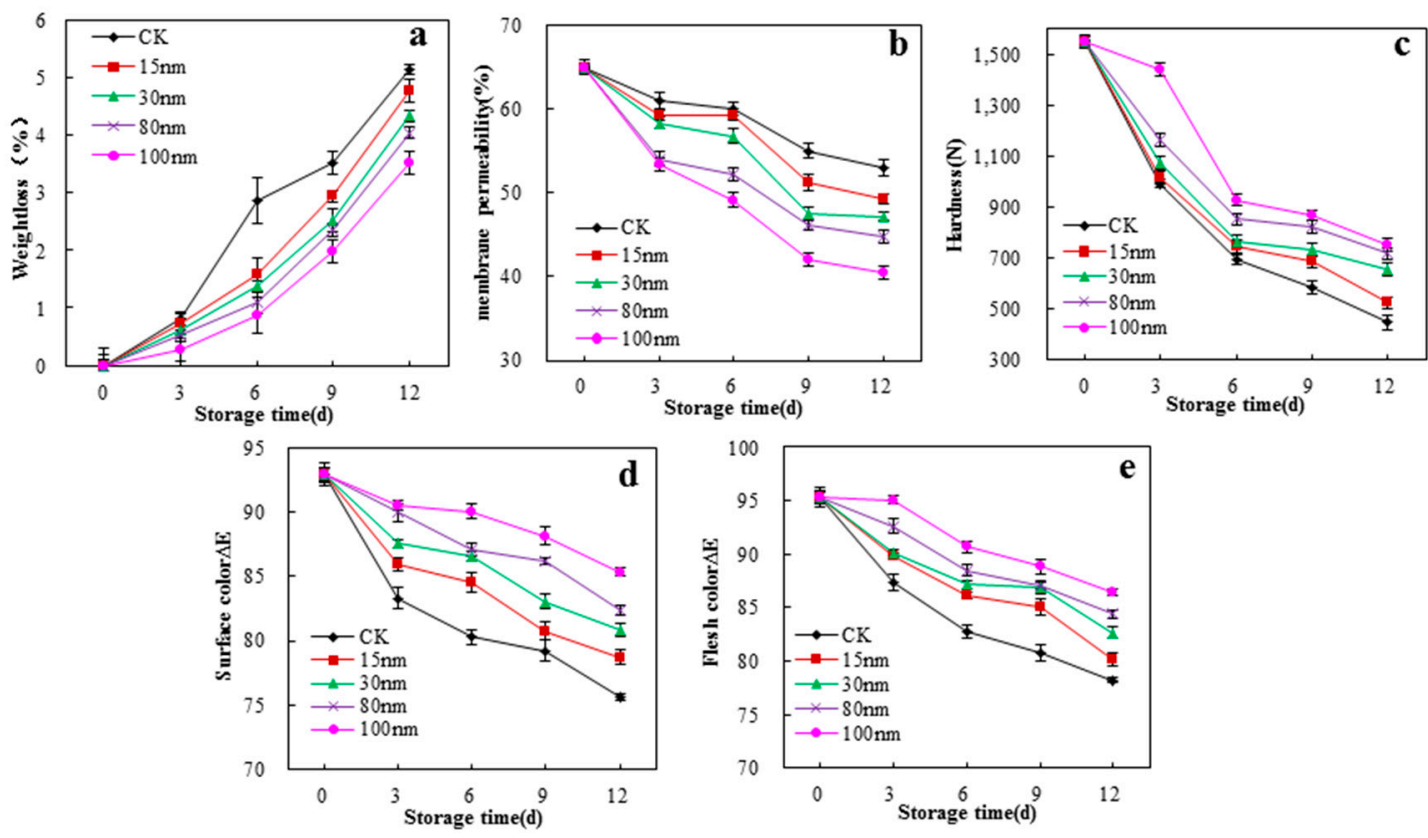

Figure 9. Effects of the films on weight loss (a), membrane permeability (b), hardness (c), surface $\Delta E$ (d), and flesh $\Delta E$ (e) of white mushroom during storage at $4 \pm 1^{\circ} \mathrm{C}$.

\section{Conclusions}

This study demonstrated that the size of nano- $\mathrm{SiO}_{2}$ played an important role in the physical and mechanical properties of potato starch films. The $100 \mathrm{~nm}$ nano- $\mathrm{SiO}_{2}$ was dispersed more uniformly in the potato starch films and the strong hydrogen bond was formed between the nano- $\mathrm{SiO}_{2}$ and potato starch molecules. The packing properties of the $100 \mathrm{~nm}$ nano- $\mathrm{SiO}_{2} /$ potato starch films were superior to those of the other films, which the WVTR, OTR, CDTR, solubility, moisture absorption, and tensile strength were $789.41 \mathrm{~g} / \mathrm{m}^{2} \cdot \mathrm{d}, 111.54 \mathrm{~g} / \mathrm{m}^{2} \cdot \mathrm{d}, 902.47 \mathrm{~g} / \mathrm{m}^{2} \cdot \mathrm{d}, 52.7 \%, 18.4 \%$ and 15.1MPa, respectively. Especially, the resistance to ultraviolet aging and thermal aging was enhanced by the incorporation of nano- $\mathrm{SiO}_{2}$. The antibacterial experiment indicated that the nano- $\mathrm{SiO}_{2} /$ potato starch films exhibited good antibacterial activity against the E. coli and was less efficient against the $S$. aureus. The effects of the preservation properties of the nano- $\mathrm{SiO}_{2} /$ potato starch films on the white mushrooms were remarkable; and those of the $100 \mathrm{~nm}$ films were superior. Further investigations should be conducted to the dispersion of nano- $\mathrm{SiO}_{2}$ with a small size in the potato starch films. The mechanism underlying the antibacterial activity of nano- $\mathrm{SiO}_{2}$ / potato starch films against microorganism, particularly those 
responsible for the pathogenic bacteria of postharvest white mushroom during storage, also needs to be expounded.

Supplementary Materials: The following are available online at http:/ /www.mdpi.com/2073-4360/10/10/1172/ s1, Figure S1: Thickness (a), OTR (b), CDTR (c), solubility (d), and moisture absorption (e) of the potato starch films with nano-SiO 2 of different sizes. Table S1: Inhibition zone diameter of potato starch films with different size of nano- $\mathrm{SiO}_{2}$ against $E$. coli and $S$. aureus.

Author Contributions: R.Z. designed the experiments. R.Z. performed the experiments, analyzed the data, and wrote the manuscript. X.W. revised the manuscript and the Funding Acquisition. M.C. performed the part of "Antibacterial activity of the films".

Funding: This work was supported by the National Natural Science Foundation of China (31301570 and 30871757$)$.

Acknowledgments: The authors thank the Analysis and Testing Center, Shandong University of Technology for providing the experimental equipment used in this study.

Conflicts of Interest: The authors declare no conflict of interest.

\section{References}

1. Vargas, C.G.; Costa, T.M.H.; Rios, A.D.O.; Flôres, S.H. Comparative study on the properties of films based on red rice (oryza glaberrima) flour and starch. Food Hydrocoll. 2017, 65, 96-106. [CrossRef]

2. Pagno, C.H.; Costa, T.M.H.; De Menezes, E.W.; Benvenutti, E.V.; Hertz, P.F.; Matte, C.R.; Tosati, J.V.; Monteiro, A.R.; Rios, A.O.; Flôres, S.H. Development of active biofilms of quinoa (Chenopodium quinoa W.) starch containing gold nanoparticles and evaluation of antimicrobial activity. Food Chem. 2015, 173, 755-762. [CrossRef] [PubMed]

3. Piñeros-Hernandez, D.; Medina-Jaramillo, C.; López-Córdoba, A.; Goyanes, S. Edible cassava starch films carrying rosemary antioxidant extracts for potential use as active food packaging. Food Hydrocoll. 2017, 63, 488-495. [CrossRef]

4. Wang, W.T.; Zhang, H.; Jia, R.; Dai, Y.Y.; Dong, H.Z.; Hou, H.X.; Guo, Q.B. High performance extrusion blown starch/polyvinyl alcohol/clay nanocomposite films. Food Hydrocoll. 2018, 79, 534-543. [CrossRef]

5. Podshivalov, A.; Zakharova, M.; Glazacheva, E.; Uspenskaya, M. Gelatin/potato starch edible biocomposite films: correlation between morphology and physical properties. Carbohydr. Polym. 2017, 157, 1162-1172. [CrossRef] [PubMed]

6. Oleyaei, S.A.; Almasi, H.; Ghanbarzadeh, B.; Moayedi, A.A. Synergistic reinforcing effect of $\mathrm{TiO}_{2}$ and montmorillonite on potato starch nanocomposite films: Thermal, mechanical and barrier properties. Carbohydr. Polym. 2016, 152, 253-262. [CrossRef] [PubMed]

7. Ortega, F.; Giannuzzi, L.; Arce, V.B.; García, M.A. Active composite starch films containing green synthetized silver nanoparticles. Food Hydrocoll. 2017, 70, 152-162. [CrossRef]

8. Sun, T.; Wu, C.L.; Hao, H.; Dai, Y.; Li, J.R. Preparation and preservation properties of the chitosan coatings modified with the in situ, synthesized nano siox. Food Hydrocoll. 2016, 54, 130-138. [CrossRef]

9. Yang, M.L.; Shi, J.S.; Xia, Y.Z. Effect of $\mathrm{SiO}_{2}$, PVA and glycerol concentrations on chemical and mechanical properties of alginate-based films. Int. J. Biol. Macromol. 2018, 107, 2686-2694. [CrossRef] [PubMed]

10. Tang, H.; Xiong, H.; Tang, S.; Peng, Z. A starch-based biodegradable film modified by nano silicon dioxide. J. Appl. Polym. Sci. 2009, 113, 34-40. [CrossRef]

11. Torabi, Z.; Mohammadinafchi, A. The effects of $\mathrm{SiO}_{2}$ nanoparticles on mechanical and physicochemical properties of potato starch films. J. Chem. Health Risks 2013, 3, 33-42.

12. Rahman, P.M.; Mujeeb, V.M.A.; Muraleedharan, K.; Thomas, S.K. Chitosan/nano-ZnO composite films: Enhanced mechanical, antimicrobial and dielectric properties. Arabian J. Chem. 2018, 11, 120-127. [CrossRef]

13. Talebian, N.; Zare, E. Structure and antibacterial property of nano-SiO ${ }_{2}$ supported oxide ceramic. Ceram. Int. 2014, 40, 281-287. [CrossRef]

14. Song, H.W.; Yuan, W.M.; Jin, P.; Wang, W.; Wang, X.F.; Yang, L.M.; Zhang, Y.F. Effects of chitosan/nano-silica on postharvest quality and antioxidant capacity of loquat fruit during cold storage. Postharvest Biol. Technol. 2016, 119, 41-48. [CrossRef]

15. Shi, S.Y.; Wang, W.; Liu, L.Q.; Wu, S.J.; Wei, Y.Z.; Li, W.C. Effect of chitosan/nano-silica coating on the physicochemical characteristics of longan fruit under ambient temperature. J. Food Eng. 2013, 118, 125-131. [CrossRef] 
16. Tabatabaei, R.H.; Jafari, S.M.; Mirzaei, H.; Nafchi, A.M.; Dehnad, D. Preparation and characterization of nano- $\mathrm{SiO}_{2}$ reinforced gelatin-kcarrageenan biocomposites. Int. J. Biol. Macromol. 2018, 111, 1091-1099. [CrossRef] [PubMed]

17. Liu, X.; Cui, Y.H.; Chen, H.Y. Influence of depositing nano-SiO ${ }_{2}$ particles on the surface microstructure and properties of jute fibers via in situ synthesis. Compos. Part A 2018, 109, 368-375. [CrossRef]

18. Ritamäki, M.; Rytöluoto, I.; Lahti, K.; Karttunen, M. Effects of thermal aging on the characteristic breakdown behavior of Nano-SiO $2-B O P P$ and BOPP films. In Proceedings of the 11th International Conference on the Properties and Applications of Dielectric Materials (ICPADM), Sydney, Australia, 19-22 July 2015.

19. Gong, C.; Yang, L.Q.; Zhou, J.C.; Xiang, G.; Zhuang, Z.X. Possible role of PAPR-1 in protecting human HaCaT cells against cytotoxicity of $\mathrm{SiO}_{2}$ nanoparticles. Toxicol. Lett. 2017, 280, 213-221. [CrossRef] [PubMed]

20. Zhao, F.C.; Zeng, X.R.; Li, H.Q.; Zhang, J. Preparation and characterization of nano-SiO $2 /$ fluorinated polyacrylate composite latex via nano-SiO $2 /$ acrylate dispersion. Colloids Surf. A 2012, 396, 328-335. [CrossRef]

21. Cui, X.; Zhong, S.; Yan, J.; Wang, C.; Zhang, H.; Wang, H. Synthesis and characterization of core-shell $\mathrm{SiO}_{2}$-fluorinated polyacrylate nanocomposite latex particles containing fluorine in the shell. Colloids Surf. A 2010, 360, 41-46. [CrossRef]

22. Fortuni, B.; Fujita, Y.; Ricci, M.; Inose, T.; Aubert, R.; Lu, G. A novel method for in situ synthesis of sers-active gold nanostars on polydimethylsiloxane film. Chem. Commun. 2017, 53, 5121. [CrossRef] [PubMed]

23. Hassannia-Kolaee, M.; Khodaiyan, F.; Pourahmad, R.; Shahabi-Ghahfarrokhi, I. Development of ecofriendly bionanocomposite: Whey protein isolate/pullulan films with nano-SiO 2 . Int. J. Biol. Macromol. 2016, 86, 139-144. [CrossRef] [PubMed]

24. Wang, L.; Xiao, M.; Dai, S.H.; Song, J.; Ni, X.W.; Fang, Y.P.; Corke, H.; Jiang, F.T. Interactions between carboxymethyl konjac glucomannan and soy protein isolate in blended films. Carbohydr. Polym. 2014, 101, 136-145. [CrossRef] [PubMed]

25. Moreno, O.; Cárdenas, J.; Atarés, L.; Chiralt, A. Influence of starch oxidation on the functionality of starch-gelatin based active films. Carbohydr. Polym. 2017, 178, 147-158. [CrossRef] [PubMed]

26. Colussi, R.; Pinto, V.Z.; Slm, E.H.; Biduski, B.; Prietto, L.; Castilhos, D.D.; Zavareze, E.D.R.; Dias, A.R.G. Acetylated rice starches films with different levels of amylose: Mechanical, water vapor barrier, thermal, and biodegradability properties. Food Chem. 2016, 221, 1614-1620. [CrossRef] [PubMed]

27. Vimala, K.; Yallapu, M.M.; Varaprasad, K.; Reddy, N.N.; Ravindra, S.; Naidu, N.S.; Raju, K.M. Fabrication of curcumin encapsulated chitosan-PVA silver nanocom posite films for improved antimicrobial activity. J. Biomater. Nanobiotechnol. 2011, 2, 55-64. [CrossRef]

28. Liu, Z.L.; Wang, X.Y.; Zhu, J.Y.; Wang, J. Effect of high oxygen modified atmosphere on post-harvest physiology and sensorial qualities of mushroom. Int. J. Food Sci. Technol. 2010, 45, 1097-1103. [CrossRef]

29. Lizundia, E.; Vilas, J.L.; Sangroniz, A.; Etxeberria, A. Light and gas barrier properties of PLLA/metallic nanoparticles composite films. Eur. Polym. J. 2017, 91, 10-20. [CrossRef]

30. Wu, C.H.; Peng, S.H.; Wen, C.R.; Wang, X.M.; Fan, L.L.; Deng, R.H.; Pang, J. Structural characterization and properties of konjac glucomannan/curdlan blend films. Carbohydr. Polym. 2012, 89, 497-503. [CrossRef] [PubMed]

31. Sahraee, S.; Milani, J.M.; Ghanbarzadeh, B.; Hamishehkar, H. Physicochemical and antifungal properties of bio-nanocomposite film based on gelatin-chitin nanoparticles. Int. J. Biol. Macromol. 2017, 97, 373-381. [CrossRef] [PubMed]

32. Ghosh Dastidar, T.; Netravali, A. Cross-linked waxy maize starch-based green composites. ACS Sustain. Chem. Eng. 2013, 1, 1537-1544. [CrossRef]

33. Yong, C.; Xie, K.; Pan, Y.; Chen, Y.; Xu, J.; Xing, X. Synthesis of Si/C/N ultrafine composite powder by pyrolysis of polynirisilicane. J. Chin. Ceram. Soc. 2000, 28, 491-493.

34. Zhao, Y.L.; Qi, X.W.; Dong, Y.; Ma, J.; Zhang, Q.L.; Song, L.Z.; Yang, Y.L.; Yang, Q.X. Mechanical, thermal and tribological properties of polyimide $/$ nano- $\mathrm{SiO}_{2}$ composites synthesized using an in-situ polymerization. Tribol. Int. 2016, 103, 599-608. [CrossRef]

35. Jiang, S.S.; Liu, C.Z.; Wang, X.J.; Xiong, L.; Sun, Q.J. Physicochemical properties of starch nanocomposite films enhanced by self-assembled potato starch nanoparticles. LWT-Food Sci. Technol. 2016, 69, 251-257. [CrossRef] 
36. Dai, L.; Qiu, C.; Xiong, L.; Sun, Q. Characterisation of corn starch-based films reinforced with taro starch nanoparticles. Food Chem. 2015, 174, 82-88. [CrossRef] [PubMed]

37. Shahabi-Ghahfarrokhi, I.; Khodaiyan, F.; Mousavi, M.; Yousefi, H. Preparation of UV-protective kefiran/Nano-ZnO nanocomposite: physical and mechanical properties. Int. J. Biol. Macromol. 2015, 72, 41-46. [CrossRef] [PubMed]

38. Kristo, E.; Biliaderis, C.G. Physical properties of starch nanocrystal-reinforced pullulan films. Carbohyd. Polym. 2007, 68, 146-158. [CrossRef]

39. Almasi, H.; Ghanbarzadeh, B.; Entezami, A.A. Physicochemical properties of starch-CMC-nanoclay biodegradable films. Int. J. Biol. Macromol. 2010, 46, 1-5. [CrossRef] [PubMed]

40. Xiong, H.G.; Tang, S.W.; Tang, H.L.; Zou, P. The structure and properties of a starch-based biodegradable film. Carbohydr. Polym. 2008, 71, 263-268. [CrossRef]

41. Farhan, A.; Hani, N.M. Characterization of edible packaging films based on semi-refined kappa-carrageenan plasticized with glycerol and sorbitol. Food Hydrocoll. 2017, 64, 48-58. [CrossRef]

42. Luchese, C.L.; Garrido, T.; Spada, J.C.; Tessaro, I.C.; La Caba, K.D. Development and characterization of cassava starch films incorporated with blueberry pomace. Int. J. Biol. Macromol. 2018, 106, 834-839. [CrossRef] [PubMed]

43. Biduski, B.; Silva, F.T.; Silva, W.M.; Halal, S.L.; Pinto, V.Z.; Dias, A.R. Impact of acid and oxidative modifications, single or dual, of sorghum starch on biodegradable films. Food Chem. 2017, 214, 53-60. [CrossRef] [PubMed]

44. Guerrero, P.; Hanani, Z.A.N.; Kerry, J.P.; Caba, K.D.L. Characterization of soy protein-based films prepared with acids and oils by compression. J. Food Eng. 2011, 107, 41-49. [CrossRef]

45. Nawab, A.; Alam, F.; Haq, M.A.; Lutfi, Z.; Hasnain, A. Mango kernel starch-gum composite films: Physical, mechanical and barrier properties. Int. J. Biol. Macromol. 2017, 98, 869-876. [CrossRef] [PubMed]

46. Zou, W.; Peng, J.; Yang, Y.; Zhang, L.; Liao, B.; Xiao, F. Effect of nano-SiO 2 , on the performance of POLY (MMA/BA/MAA)/EP. Mater. Lett. 2007, 61, 725-729. [CrossRef] 